\title{
Reabilitação bucal em ambiente hospitalar em paciente com Disceratose Congênita e Doença Periodontal Generalizada: relato de caso
}

\author{
Bárbara Soldatelli Ballardin, Arthur Magno Medeiros de Araújo, Geisla Mary Silva \\ Soares, José Miguel Amenábar, Juliana Lucena Schussel, Cassius Carvalho Torres- \\ Pereira, Roberta Targa Stramandinoli-Zanicotti*
}

Programa de Residência Multiprofissional em Atenção Hospitalar com área de concentração em Oncologia e Hematologia - Complexo Hospital de Clínicas da Universidade Federal do Paraná, Curitiba, PR, Brasil

\section{Histórico do Artigo Recebido em: 08/01/2020 \\ Aceito em: \\ $21 / 02 / 2020$ \\ Palavras-chave: Disceratose congênita; prótese total, unidade hospitalar de odontologia; reabilitação bucal; doenças periodontais; hematologia}

Keywords: Dyskeratosis congenita; denture complete; dental service hospital; mouth rehabilitation; periodontal diseases; hematology

\begin{abstract}
RESUMO
A Disceratose Congênita (DC) é uma genodermatose genética rara com predileção pelo sexo masculino onde o paciente diagnosticado com a doença pode desenvolver alterações em diversos órgãos. A doença caracteriza-se por uma tríade patognômonica que facilita o diagnóstico final da doença, a qual é composta por pigmentação reticular da pele, distrofia ungueal e leucoplasias bucais. Pacientes com DC desenvolvem falência medular associada a manutenção anormal dos telômeros, sendo o Transplante de Células-Tronco Hematopoiéticas (TCTH) alogênico a única possibilidade de cura. Além das placas brancas orais características da doença, o paciente com DC pode apresentar outras manifestações bucais, como, por exemplo, a doença periodontal. As leucoplasias orais devem receber maior atenção por apresentarem potencial de malignização. O objetivo deste trabalho é relatar o caso de um paciente do sexo masculino, com 23 anos de idade, diagnosticado com DC, que após estabelecimento de doença periodontal severa, necessitou da exodontia de todos os dentes e posterior reabilitação protética bucal, realizada em ambiente hospitalar. A confecção de próteses totais não é rotineira em ambiente hospitalar, assim, esse caso torna-se relevante por relatar a reabilitação bucal em paciente jovem com doença sistêmica rara. A reabilitação protética possibilitou o restabelecimento da estética, função e autoestima do paciente, interferindo significativamente em sua qualidade de vida e reintegração social e familiar.
\end{abstract}

Oral rehabilitation in a hospital environment in a patient with congenital dyskeratosis and generalized periodontal disease: case report

\section{ABSTRACT}

Congenital Dyskeratosis (CD) is a rare genetic genodermatosis with male predilection where the patient diagnosed with the disease may develop changes in several organs. The disease is characterized by a pathognomonic triad that facilitates the final diagnosis of the disease, which is composed by reticular pigmentation of the skin, nail dystrophy and oral leukoplakias. Oral lesions should receive greater attention because of their potential for malignancy. Because they develop spinal cord failure associated with abnormal telomere maintenance, the only treatment that enables healing is Allogeneic Hematopoietic Stem Cell Transplant (HSCT). In addition to oral white plaques characteristic of the disease, patients with $\mathrm{CD}$ may have other oral manifestations, such as periodontal disease. The objective of this study is to report the case of a 23 -year-old male patient diagnosed with $\mathrm{CD}$ who, after severe periodontal disease, required the extraction of all teeth and subsequent oral prosthetic rehabilitation, performed in a hospital environment. The making of total dentures is not routine in a hospital environment, so this case becomes relevant because of the rarity of the disease and because it is a young patient who needs total dentures after untreated periodontal disease. Prosthetic rehabilitation enabled the restoration of the aesthetics, function and self-esteem of the patient, significantly interfering in his quality of life and social and family reintegration.

\section{Introdução}

A Disceratose Congênita (DC) é uma genodermatose genética rara com predileção

\footnotetext{
*Autor Correspondente: robertastramandinoli@yahoo.com.br (Stramandinoli-Zanicotti R.T.)
} 
pelo sexo masculino e que geralmente se desenvolve nos primeiros 10 anos de vida (1). Por sua raridade, existem poucos casos relatados no mundo (2). O paciente com DC pode desenvolver alterações dentárias, gastrintestinais, geniturinárias, neurológicas, oftalmológicas, pulmonares e esqueléticas (1-3). Além disso, ainda apresentam maior predisposição para o desenvolvimento de tumores sólidos, como, por exemplo, o câncer de boca $(1,3)$. O Carcinoma Espinocelular (CEC) é o tipo mais comum de câncer de boca, e seu diagnóstico em indivíduos com DC está relacionado com as leucoplasias orais características da doença, sendo que essa é considerada uma lesão cancerável.

A doença apresenta alguns sinais patognomônicos, sendo estes agrupados em uma tríade, que, na maioria das vezes, facilita a chegada ao diagnóstico final. A tríade é composta por pigmentação reticulada da pele, distrofia ungueal e lesões leucoplásicas em mucosas $(1,3)$. Em boca, as lesões são mais frequentes em língua e mucosa jugal. Essas, portanto, apresentam potencial de malignização, e, por esse motivo, pacientes com DC devem ter um rigoroso acompanhamento Odontológico (1). A pigmentação reticulada da pele afeta principalmente a face, o pescoço e a parte superior do tórax (1).

A DC se encaixa em um grupo de doenças conhecido como Síndromes de Falência Medular, pois uma de suas consequências é a aplasia da medula $(1,2)$. A falha medular está relacionada com a manutenção anormal dos telômeros $(1,2,4)$ e está fortemente relacionada com a morte precoce dos indivíduos portadores da doença. Para a recuperação da hematopoiese do paciente diagnosticado com falência medular associada a DC, o Transplante de Células-Tronco Hematopoiéticas alogênico se faz necessário (1-4).

Além das placas brancas bucais que complementam a tríade patognomônica da DC, os pacientes também podem apresentar taurodontismo, hipodontia, sangramento gengival, inflamação gengival, perda de inserção clínica periodontal e perda óssea, o que pode simular uma periodontite agressiva $(1,5-7)$. Os pacientes com DC podem ter maior predisposição para desenvolver doença periodontal, e nesses casos, com características de maior severidade (1). Um estudo de Karunakaran et al. (2013) relata que $80 \%$ de toda a população diagnosticada com DC apresenta leucoplasias orais, 5\% pode apresentar alterações no tamanho na relação raiz e coroa dentária e 57\% pode apresentar taurodontismo leve.

Para confirmação diagnóstica de DC, outras doenças genéticas precisam ser descartadas, como, por exemplo, a Anemia de Fanconi (6).

\section{Aspectos Éticos}

Esse trabalho trata-se do relato de caso de um paciente diagnosticado com DC que realiza acompanhamento médico e multiprofissional no Complexo Hospital de Clínicas da Universidade Federal do Paraná, que está localizado em Curitiba - PR. O caso clínico faz parte de um estudo retrospectivo e descritivo que engloba pacientes portadores de DC, onde foi realizada revisão dos prontuários de todos os pacientes atendidos no Serviço de Transplante de Medula Óssea (STMO) desse hospital, que haviam sido diagnosticados com DC no período de janeiro 1997 a dezembro de 2017. O estudo foi aprovado pelo Comitê de Ética e Pesquisa do mesmo hospital (CAAE: 65892217.8.0000.0096).

\section{Relato de caso}

Paciente do sexo masculino, 23 anos, diagnosticado com DC aos 7 anos de idade, tendo dois irmãos também portadores da doença, e, por decorrência do diagnóstico e da possibilidade de aplasia medular, realiza acompanhamento multiprofissional na 
instituição. Apresentava-se estável, sem uso de medicamentos, porém, com plaquetopenia persistente, a qual era restabelecida com transfusões sanguíneas de suporte, realizadas conforme a necessidade, sendo essa verificada pelo acompanhamento hematológico. Procurou a equipe de Odontologia do STMO com queixa de sensibilidade dentária generalizada e dificuldade em se alimentar. Ao exame físico intra-oral foi possível identificar placas brancas em dorso lingual, sendo essas lesões compatíveis com as manifestações bucais que complementam a tríade característica da doença. Além disso, observou-se perdas dentárias, cálculo dentário, acúmulo de biofilme bacteriano, dentes remanescentes com mobilidade grau I, II e III e cáries dentárias extensas, as quais podem ser observadas na Figura 1.

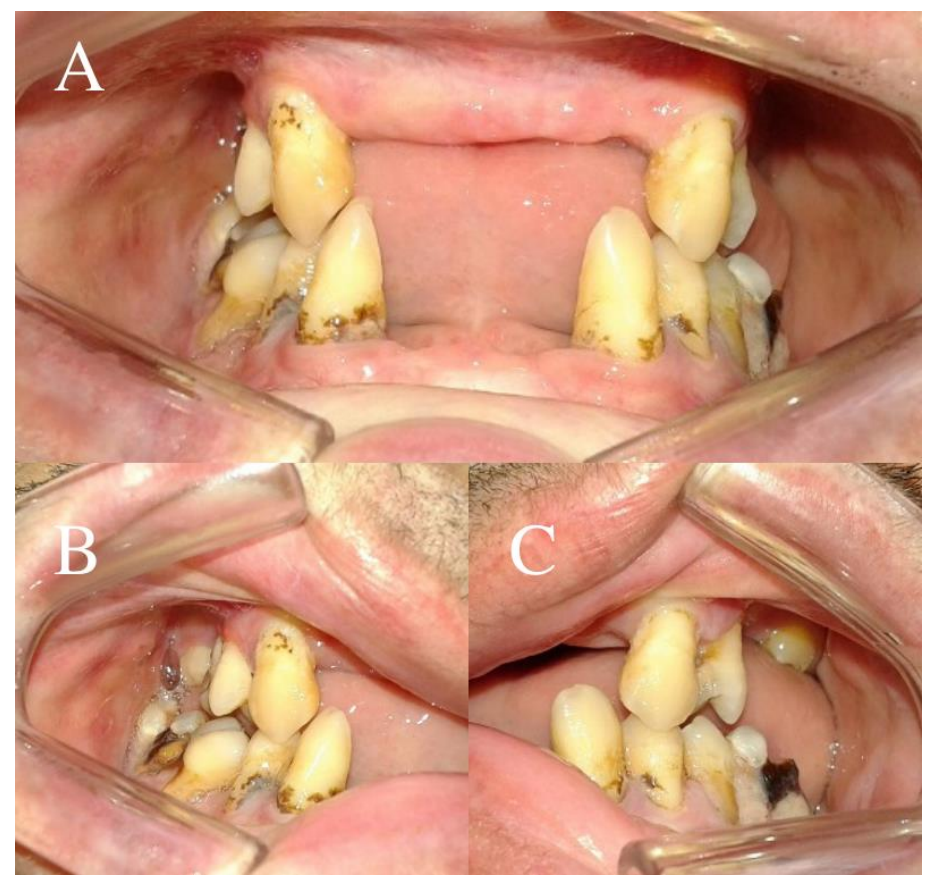

Figura 1 - Em A temos uma visão geral dos dentes remanescentes do paciente; em B, ampliação do lado direito; em C, ampliação do lado esquerdo.

Para melhor diagnóstico e avaliação do caso, solicitou-se radiografia panorâmica (Figura 2), onde verificou-se a presença de perda óssea severa, nos trazendo a hipótese diagnóstica de periodontite agressiva generalizada.

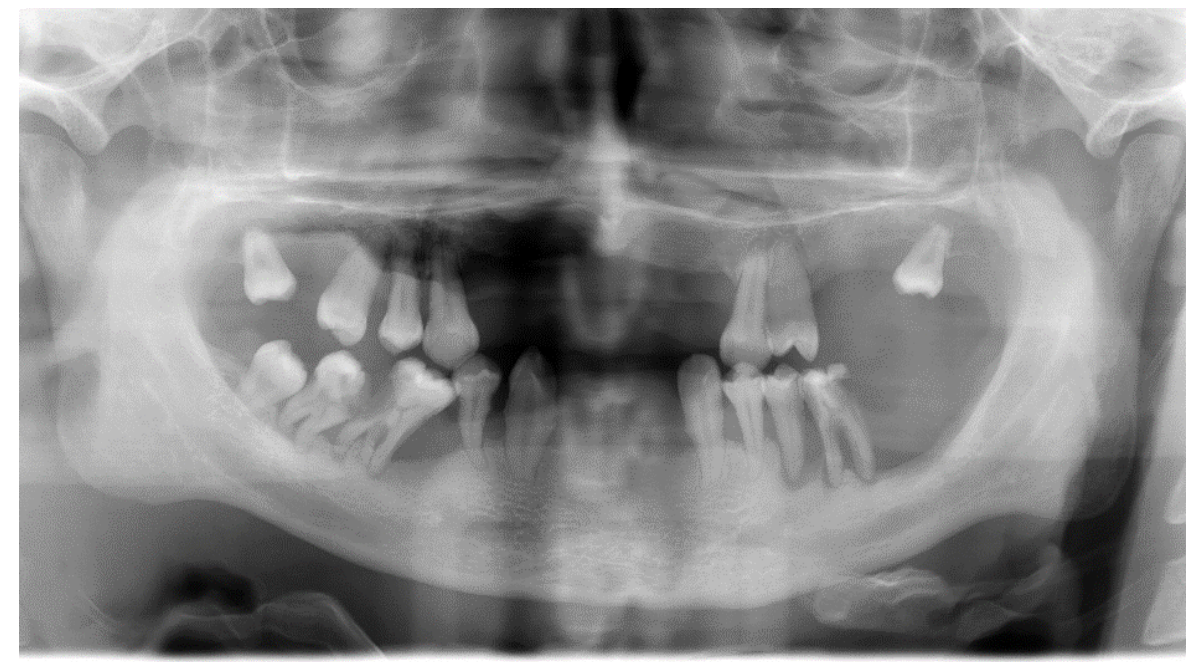

Figura 2 - Radiografia panorâmica inicial. 
O paciente e seus familiares apresentavam-se vulneráveis economicamente e socialmente. Sendo procedentes de outro estado, relatavam não conseguir atendimento odontológico frequente na cidade de origem. Frente às condições de saúde bucal do paciente, levando em consideração a possibilidade de TCTH para correção de falência medular, a vulnerabilidade social do paciente e seus familiares, e o retorno semestral ao hospital para acompanhamento médico e odontológico, optou-se pela exodontia de todos os dentes. No momento dos procedimentos cirúrgicos, este encontrava-se sem indicação para TCTH e com 43 mil plaquetas. Como conduta prévia à intervenção cirúrgica, a transfusão plaquetária foi prescrita, além de antibioticoterapia (amoxicilina) e corticoesteroides (dexametasona). Assim, realizou-se as exodontias de todos os dentes em ambiente ambulatorial, sob anestesia local (sal anestésico lidocaína $2 \%$ com vasoconstritor epinefrina 1:100.000), apresentando sangramento compatível com as condições sistêmicas e sem intercorrêncas. Como prescrição pós-operatória manteve-se a antibioticoterapia e prescreveu-se analgésico (dipirona) e enxaguante bucal antimicrobiano (clorexidina $0,12 \%$ ). Na avaliação pós-operatória imediata, observou-se áreas sem formação de coágulo e com sangramento leve, porém, contínuo. Por esse motivo, para maior segurança do paciente, nova transfusão plaquetária foi realizada. $\mathrm{O}$ processo cicatricial evoluiu naturalmente, possibilitando seu retorno à cidade de origem. Pela vulnerabilidade econômica e social já comentada, não havia possibilidade da confecção de suas próteses em instituições onde fossem necessárias ajuda de custo. Com o incentivo de instituições que apoiam o STMO desse hospital, as próteses totais superior e inferior puderam ser confeccionadas em ambiente hospitalar. Por intervenção da equipe do Serviço Social, o paciente retornou à Curitiba para planejamento da reabilitação oral e foi mantido na cidade com suas despesas custeadas até a finalização do tratamento odontológico. Para planejamento da reabilitação e melhor avaliação, um novo exame de imagem foi solicitado (Figura 3).

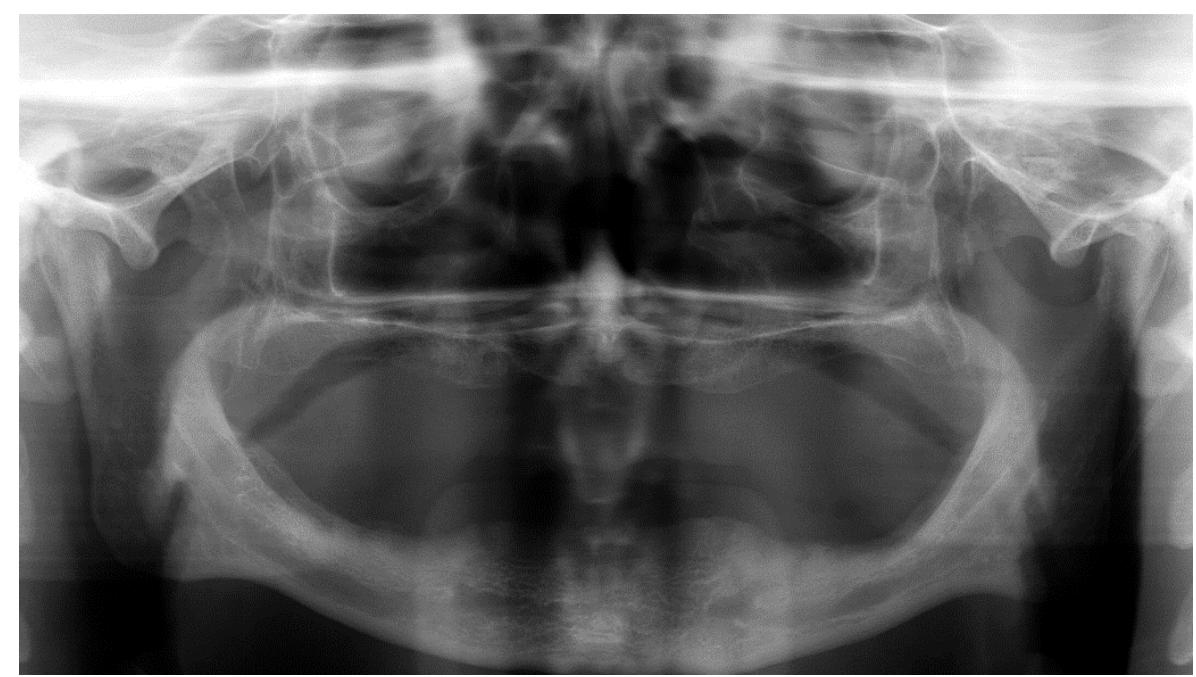

Figura 3 - Radiografia panorâmica após exodontias múltiplas.

Assim, realizou-se todos os procedimentos necessários para confecção de duas próteses totais, as quais foram instaladas e seus ajustes foram realizados, proporcionamento melhor conforto e adaptação. Orientações sobre a adaptação, uso e higiene das próteses foram repassados ao paciente e a mãe, sua principal cuidadora. A dimensão vertical de oclusão foi restabelecida. A intervenção cirúrgica e a reabilitação protética possibilitaram alimentação balanceada e equilíbrio da saúde bucal e geral do paciente. Os resultados finais após conclusão do tratamento odontológico podem ser 
visualizados na Figura 4.

Pacientes diagnosticados com DC, por apresentarem risco de desenvolver falência medular, podem ser submetidos a TCTH para tratamento dessa consequência. Para a realização de TCTH com o mínimo de intercorrências possíveis, se faz necessária a remoção de focos infecciosos orais e manutenção da saúde bucal, evitando reinternações e diminuindo o risco de infecções oportunistas. O paciente em questão, apesar de, no momento da intervenção odontológica não ter previsão para transplante, posteriormente, foi submetido a essa terapêutica. Sua saúde bucal já havia sido restabelecida anteriormente, necessitando apenas de orientações e não mais de intervenções odontológicas. O paciente realizou o TCTH com boa saúde bucal, reabilitado, diminuindo possíveis desconfortos que poderia enfrentar caso fosse submetido ao transplante com as condições de saúde bucal inicialmente identificadas.

É protocolo da Equipe de Odontologia do STMO que os pacientes submetidos à TCTH passem por avaliação pré-transplante e sejam monitorados no internamento e também em seu período no hospital dia, que trata-se de um acompanhamento ambulatorial, tendo, normalmente, duração de 100 dias após o transplante. Durante o internamento para TCTH, o paciente não utilizou as próteses dentárias por tê-las esquecido na cidade de origem. Porém, é recomendação da equipe a não utilização durante o período de condicionamento quimioterápico, com o objetivo de evitar traumas às mucosas orais que apresentam-se mais sensíveis devido aos diversos medicamentos utilizados.

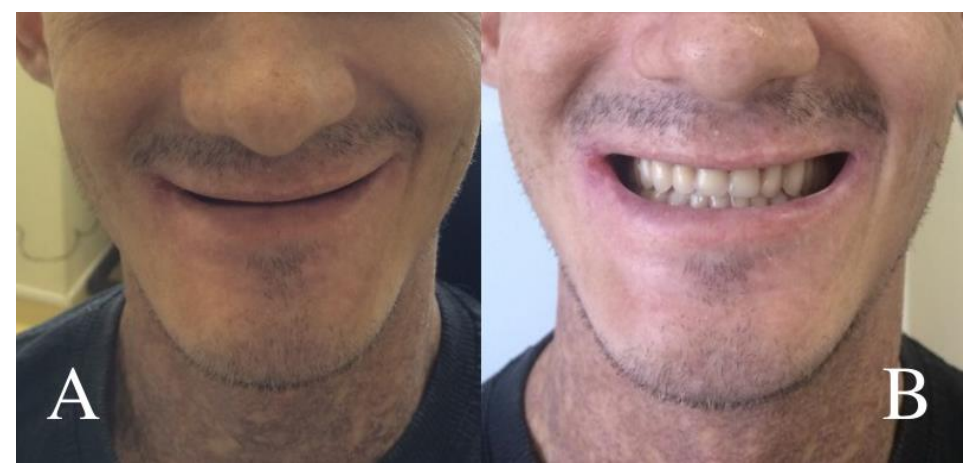

Figura 4 - Imagem comparativa. Em A, paciente sorrindo sem as próteses dentárias. Em B, paciente sorrindo utilizando as próteses dentárias.

\section{Considerações Finais}

A instituição onde o procedimento de reabilitação bucal foi efetivado realiza apenas procedimentos odontológicos simples, como os encontrados na atenção básica, de acordo com os recursos disponibilizados no hospital. Assim, próteses odontológicas não são realizadas, sendo esse um caso relevante não só para o paciente, mas também para a instituição, por se tratar de uma reabilitação protética total em indivíduo jovem, com doença sistêmica grave rara, em ambiente hospitalar. Essa reabilitação bucal possibilitou que um jovem, desdentado total, pudesse ter sua estética restabelecida, sua alimentação facilitada, sua autoestima devolvida, e, consequentemente, melhora em sua qualidade de vida e reintegração social.

Esse relato de caso intensifica à importância do acompanhamento odontológico frequente de pacientes com DC, sendo que esses podem apresentar diversas manifestações bucais. A proservação das leucoplasias possibilita à prevenção do câncer de boca e/ou seu diagnóstico precoce (5). Por apresentarem maior predisposição de desenvolvimento de doença periodontal $(5,7)$, a manutenção da saúde bucal desses 
pacientes pode evitar o diagnóstico de outros casos com gravidade semelhantes à este.

\section{Referências}

1. Fernandez Garcia MS, Teruya-Feldstein J. The diagnosis and treatment of dyskeratosis congenita: a review. J Blood Med 2014; 5:157-67.

2. Ayas, M. Hematopoietic cell transplantation in Fanconi anemia and dyskeratosis congenita: A minireview. Hematology/Oncology and Stem Cell Therapy 2017: 10(4): 285-289.

3. Fioredda F, Iacobelli S, Korthof ET, Knol C, Biezen, A, Bresters D, Veys P, Yoshimi A, Faglione F, Mats B, Zecca M, Faraci M, Miano M, Arcuri L, Maschan M, O’Brien T, Diaz MA, Sevilla J, Smith O, Latour RP, Fuente J, Or R, Van Lint MT, Tolar J, Aljurf M, Fisher A, Skorobogatova EV, Heredia CD, Risitano A, Dalle J, Sedlacek, P, Ghavamzadeh A, Dufour C. Outcome of haematopoietic stem cell transplantation in dyskeratosis congenita. British Journal of Haematology 2018; 183 (1): 110-118.

4. Agarwal S. Evaluation and Management of Hematopoietic Failure in Dyskeratosis Congenita. Hematology/Oncology Clinics of North America 2018; 32(4): 669-685.

5. Ganesh D, Sreenivasan P, Ohman J, Wallstrom M, Braz-Silva PH, Giglio D, Kjeller G, Hasseus B. Potentially Malignant Oral Disorders and Cancer Transformation. Anticancer Research 2018: 38(6): 3223-3229.

6. Karunakaran, A, Ravindran, R, Arshad, M, Ram, MK, Laxmi, MKS. Dyskeratosis Congenita: A Report of Two Cases. Case Reports in Dentistry 2013; 845125.

7. Wald, C, Diner, H. Dyskeratosis congenita with associated periodontal disease. Oral Surgery, Oral Medicine, Oral Pathology 1974; 37(5): 736-744. 